\title{
Expression of a humanized single-chain variable fragment antibody targeting chronic myeloid leukemia cells in Escherichia coli and its characterization
}

\author{
XIAOYING ZHU $^{1 *}$, DONG WANG $^{1 *}$, SHENFENG LI $^{1}$, QING XIAO $^{2}$, \\ $\mathrm{KUN} \mathrm{TAO}^{1}$, JING HU ${ }^{1}$, WEIXI CAO ${ }^{1}$ and WENLI FENG ${ }^{1}$ \\ ${ }^{1}$ Key Laboratory of Laboratory Medical Diagnostics, Ministry of Education, Department of Laboratory Medicine, \\ Chongqing Medical University, ${ }^{2}$ Department of Hematology, The First Affiliated Hospital, \\ Chongqing Medical University, Chongqing 400016, P.R. China
}

Received November 30, 2011; Accepted January 19, 2012

DOI: $10.3892 / \mathrm{ijmm} .2012 .906$

\begin{abstract}
Chronic myeloid leukemia (CML) is a malignant blood disease originating from hematopoietic stem cells. Drug resistance and tumor recurrence have become major problems for the treatment of this disease. Therefore, new therapeutic methods need to be developed. Antigens expressed on the surface of cancer cells are potential targets for antibody-mediated drug delivery. In our study, an anti-CML cell single-chain variable fragment ( $\mathrm{scFv}$ ) antibody has been produced and characterized because it is the first step towards the construction of a novel cancer-targeted agent for cancer diagnosis and treatment. Here, a $46 \mathrm{kDa}$ antibody derivative was produced by genetic fusion of a humanized $\mathrm{scFv}$ antibody against a CML cell surface antigen with the 6xHis-tag, which can specifically bind to CML cells. The recombinant $\mathrm{scFv}$ against CML cells was expressed as a fusion protein containing the 6xHis-tag at its $\mathrm{N}$-termini, and purified by $\mathrm{Ni}^{2+}$-NTA column chromatography. The recombinant $\mathrm{scFv}$, which was soluble, was expressed and produced in bacteria, and was confirmed by sodium dodecyl sulfate polyacrylamide gel electrophoresis (SDS-PAGE) and western blot assays. Finally, its cell-binding activity and immunoactivity were demonstrated by enzyme-linked immunosorbent assay (ELISA). Furthermore, flow cytometry analysis demonstrated that this scFv specifically targeted CML cells expressing the associated antigen (47.9 and 34.4\%) other than non-expressing tumor cells $(1.25 \%)$ in vitro. The results presented in this study
\end{abstract}

Correspondence to: Dr Wenli Feng, Key Laboratory of Laboratory Medical Diagnostics, Ministry of Education, Department of Laboratory Medicine, Chongqing Medical University, Chongqing 400016, P.R. China

E-mail: fengwlcqmu@sina.com

${ }^{*}$ Contributed equally

Key words: chronic myeloid leukemia, tumor cell surface antigen, humanized single-chain variable fragment, cancer-targeting illustrate that the humanized anti-CML cell scFv antibody may function as a novel therapeutic tool for CML.

\section{Introduction}

Monoclonal antibodies (mAb) have been widely used in medicine, biology, immunology since Köhler and Milstein invented the hybridoma technology in 1975 (1). They have broad applications in diagnosing and treating a wide range of diseases due to their high specificity and affinity to the target cell surface or the intracellular antigen (2,3). However, as most mAbs derived from mice, the human anti-mouse antibody reaction (HAMA) can be induced by long-term administration (4). Moreover, intact $\mathrm{mAbs}$ are generally too large to penetrate tumor tissues, which limited their efficacy in clinical applications (5). With improvements in gene engineering technology, human origin antibodies, chimeric antibodies and single chain Fv are developed to progress murine origin mAbs (6-8).

Single-chain variable fragments (scFvs) are smaller fragments composed of antibody heavy ( $\mathrm{VH}$ ) and light chain variable (VL) regions with a flexible peptide linker containing 15-20 amino acids (9-11). scFvs are potentially very useful designer tools for the targeted delivery of drugs, toxins, or radionuclides to specific tumor tissues or cells (12). Compared with the larger Fab', F(ab')2, and IgG forms of the monoclonal antibodies from which they are derived, scFvs manifest lower retention times in non-target tissues, more rapid blood clearance, better tumor penetration, and decreased immunogenicity. Moreover, scFv antibodies can be produced in microbial expression systems in high yields, resulting in a fast and cost-effective production (13-16). These characteristics make scFvs potentially useful in cancer diagnosis and treatment as an effective carrier, making them attractive for therapeutic or diagnostic applications. Significant success has been achieved in this area (17-19). However, there is no $\mathrm{scFv}$ with specific targeting properties to chronic myeloid leukemia (CML) (20).

In this study, we have cloned a gene coding for the $\mathrm{scFv}$ domain from screened CML cell-specific mAb, then grafted the complementary determining regions (CDRs) of the mouse $\mathrm{VH}$ and VL genes to a human heavy chain and light chain 
variable region genes with the highest homology, and assembled them with linker peptide $\left(\mathrm{Gly}_{4} \mathrm{Ser}\right)_{3}$ to form a humanized scFv fragment (VH-linker-VL). Then the T7-RNA polymerase based pET system was used to express the $\mathrm{scFv}$ protein in Escherichia coli $(E$. coli). scFv fragments were subsequently cloned into the pET-32a(+) vector, in which the genes of the humanized $\mathrm{scFv}$ were tagged with an N-terminal 6xHis-tag to allow easy purification. The expression, solubility, specificity, and antigen-binding activity of the humanized $\mathrm{scFv}$ have been characterized in vitro.

\section{Materials and methods}

Materials. Restriction enzymes, T4 DNA ligase, dNTP and primerstar DNA polymerase were purchased from Takara Bio, Inc. (Dalian, China). $\mathrm{Ni}^{2+}$-NTA agarose was purchased from Qiagen China Co., Ltd. (Shanghai, China). Anti-6xHis mouse monoclonal antibody was purchased from ZhongShan GoldenBridge Biotechnology Co., Ltd. (Beijing, China). Horseradish peroxidase (HRP)-conjugated goat anti-mouse IgG and FITC-conjugated goat anti-mouse IgG were purchased from Beijing Huamei Biotechnology (Beijing, China). Primers were synthesized by Shanghai Sangon Biotechnology (Shanghai, China). All other chemical reagents were of analytical grade.

Bacteria culture and plasmids. E. coli DH5 $\alpha$ and BL21 (DE3) were used as host strains for cloning and expression in $E$. coli. The E. coli expression vector pET-32a(+) (Novagen) was used for constructing plasmid vector. The strains containing expression vector pET-32a(+) were grown in Luria-Bertani (LB) broth ( $1 \%$ polypeptone, $1 \% \mathrm{NaCl}$, and $0.5 \%$ yeast extract, $\mathrm{pH} 7.0$ ) or on LB agar supplemented with ampicillin $(100 \mu \mathrm{g} / \mathrm{ml})$. All strains were cultured at $37^{\circ} \mathrm{C}$ with constant shaking $(210 \mathrm{rpm})$.

Construction, expression, purification, and identification of $s c F v$. Anti-CML cells $\mathrm{scFv}$ vector named pUCT vector was constructed previously and originated from pUC57 vector (Shanghai Sangon Biotechnology). Briefly, mRNA was extracted from $5 \times 10^{6}$ hybridoma cells and cDNA was synthesized by reverse transcription reaction. $\mathrm{VH}$ and VL gene were separately amplified from the cDNA by polymerase chain reaction (PCR). Then, the obtained VH and VL gene were cloned into pMD19-T vector (Takara Bio, Inc.), and transformed into $E$. coli $\mathrm{DH} 5 \alpha$. The plasmids were identified by colony PCR and DNA sequencing. In http//www.imgt.org/ IMGT_vquest/vquest, we blasted the sequences with human antibody sequences, and found that the murine $\mathrm{VH}$ had the highest homology with the human immunoglobulin heavy chain VI-2 gene (GenBank accession no. X62106) and the base pairing rate was $75.61 \%$; the murine VL had the highest homology with the human immunoglobulin VKN light chain B1 gene (GenBank accession no. X12682) and its base pairing rate was $75.6 \%$. By the DNA recombinant techniques, the CDR domains of the murine antibody $\mathrm{VH}$ and $\mathrm{VL}$ replaced the CDR domains of the corresponding variable region sequences, respectively. The linker DNA sequence, encoding a 15 residues long flexible peptide $\left(\mathrm{Gly}_{4} \mathrm{Ser}\right)_{3}$, were used to link the humanized variable region of heavy chain with the humanized variable region of the light chain, to form a humanized $\mathrm{scFv}$ fragment (VH-linker-VL). The recombinant fragment was constructed and sequenced in Shanghai Sangon Biotechnology.

Then the cDNA encoding the humanized scFv was amplified by PCR using primers $\mathrm{P}_{1}$ and $\mathrm{P}_{2} . \mathrm{P}_{1}$ for EcoRI, 5'-CGGAATTCCAGGTGCAGCTGGTGCAGTCTG-3'; $\mathrm{P}_{2}$ rev-HindIII, 5'-CCCAAGCTTCTATTATGATCTCCACCTT GGTCCCTCCGC-3' used to introduce the EcoRI and HindIII restriction sites (underlined) were synthesized in Shanghai Sangon Biotechnology. Then the products were digested with EcoRI and HindIII, and inserted into the EcoRI/HindIII sites of pET32a(+) vector. The resultant plasmid was designated as pET32a-scFv. Furthermore, the pET32a-scFv plasmid was confirmed by restriction enzyme digestions, colony PCR and DNA sequencing, and the clones with an insert orientation preserving the direction of transcription from the $\mathrm{T} 7$ promoter were selected.

Expression of $s c F v$ gene. The humanized $\mathrm{scFv}$ expressing bacteria were subsequently obtained by transformation of the constructed $\mathrm{pET} 32 \mathrm{a}-\mathrm{ScFv}$ recombinant plasmid into the BL21 (DE3) expression strain. LB media $(1 \mathrm{ml})$ was added to the cells and mixed gently. The cells were then incubated at $37^{\circ} \mathrm{C}$ for $1 \mathrm{~h}$ at $210 \mathrm{rpm}$ in a platform shaking incubator (Bioline Series 4600, Edwards Instrument Co., Australia) before an aliquot of $100 \mu \mathrm{l}$ was spread onto an LB/amp plate and incubated at $37^{\circ} \mathrm{C}$ for $12 \mathrm{~h}$. The positive expression clones were subsequently screened out by colony PCR. The sequences amplified by PCR were confirmed by nucleotide sequencing.

Expression was induced by iso-propyl- $\beta$-D-thiogalactoside (IPTG) (Takara Bio, Inc.) at a final concentration of $1.0 \mathrm{mM}$ at $25^{\circ} \mathrm{C}$ for various time durations. In order to find the optimal induction conditions, a time course experiment was performed using log phase pET32a-scFv transformed BL21 (DE3) cells, and $1.0 \mathrm{mM}$ IPTG was added to induce protein expression after OD 600 reached 0.4-0.6. Then $1 \mathrm{ml}$ samples were taken at each time-points: 3, 4, 5 and $6 \mathrm{~h}$ after induction and lysed by sonication in ice water bath. The cell pellets collected from the protein expression cultures induced for $4 \mathrm{~h}$ were lysed with 1 XHis binding buffer $(20 \mathrm{mM}$ Tris- $\mathrm{HCl}, 500 \mathrm{mM} \mathrm{NaCl}$, $1 \mathrm{mM}$ imidazole, $\mathrm{pH} 8.0$ ) and frozen at $-80^{\circ} \mathrm{C}$ for $30 \mathrm{~min}$. The cell pellets were then sonicated for $5 \mathrm{~min}$ and centrifuged at $16,000 \mathrm{x} g$ for $30 \mathrm{~min}$. The clear lysates, including the soluble protein remained in the supernatant and the insoluble protein found in the pellet, were applied to $10 \%$ SDS-PAGE for identification of the expression and localization of the protein.

Then $40 \mathrm{ml}$ of overnight culture of pET32a-scFv transformed BL21 (DE3) was used to inoculate to 2 liters of fresh LB/amp medium for large-scale protein production. The cells were cultured at $37^{\circ} \mathrm{C}$ for $4 \mathrm{~h}$ at $210 \mathrm{rpm}$ in a shaking incubator until OD600 reached 0.4-0.6, and then 1.0 mM IPTG was added to induce protein expression. The culture was incubated for $4 \mathrm{~h}$ at $25^{\circ} \mathrm{C}$ at $180 \mathrm{rpm}$ before harvesting the cells by centrifugation at $13,000 \mathrm{rpm}$ for $5 \mathrm{~min}$ at room temperature. The pellet was reserved at $-80^{\circ} \mathrm{C}$.

Protein purification. The $\mathrm{scFv}$ protein was purified with nickel-nitrilotriacetic acid $\left(\mathrm{Ni}^{2+}-\mathrm{NTA}\right)$ agarose resin column (Novagen). Frozen cell pellets, harvested from protein expression cultures were thawed for $15 \mathrm{~min}$ on ice and suspended with $5 \mathrm{ml}$ of $1 \mathrm{XHis}$ binding buffer $(20 \mathrm{mM}$ Tris- $\mathrm{HCl}, 500 \mathrm{mM}$ 
$\mathrm{NaCl}, 1 \mathrm{mM}$ imidazole, $\mathrm{pH}$ 8.0) per gram wet weight. The cells were lysed by sonification in ice water mixture for $20 \mathrm{~min}$. The lysate was then centrifuged at $16,000 \times \mathrm{g}$ for $30 \mathrm{~min}$ at $4^{\circ} \mathrm{C}$ to precipitate the cellular debris and the supernatant was filtered through $0.45 \mu \mathrm{m}$ filters for affinity purification. Then the lysate-resin mixture was mixed gently and rested at $4^{\circ} \mathrm{C}$ for $20 \mathrm{~min}$ in the column. After two gradient washing with wash buffer 1 (20 mM Tris- $\mathrm{HCl}, 500 \mathrm{mM} \mathrm{NaCl}, 10 \mathrm{mM}$ imidazole, $\mathrm{pH} 8.0)$ and wash buffer $2(20 \mathrm{mM}$ Tris- $\mathrm{HCl}, 500 \mathrm{mM} \mathrm{NaCl}$, $20 \mathrm{mM}$ imidazole, $\mathrm{pH} 8.0$ ), the protein was eluted with $10 \mathrm{ml}$ of elution buffer 1 (20 mM Tris- $\mathrm{HCl}, 500 \mathrm{mM} \mathrm{NaCl}, 150 \mathrm{mM}$ imidazole, $\mathrm{pH} 8.0)$ and with $10 \mathrm{ml}$ of elution buffer $2(20 \mathrm{mM}$ Tris- $\mathrm{HCl}, 500 \mathrm{mM} \mathrm{NaCl}, 250 \mathrm{mM}$ imidazole, $\mathrm{pH}$ 8.0). The eluted scFvs protein were dialyzed against $1 \mathrm{X}$ phosphate-buffered saline (PBS) $\left(\mathrm{pH} \mathrm{8.5)}\right.$ at $4^{\circ} \mathrm{C}$ to make the concentration of imidazole up to $0 \mathrm{mM}$ and then the protein preparations were filtrated, sterilized and stored at $-80^{\circ} \mathrm{C}$.

SDS-PAGE and western blotting. The purity of the purified $6 \mathrm{xHis}-\mathrm{scFv}$ protein was examined by $10 \%$ SDS-PAGE with Coomassie blue G-250 staining. Meanwhile, a BCA protein assay was performed and equivalent amounts of each protein were identified by $10 \%$ SDS-PAGE, and then transferred to PVDF membrane and immunoblotted with anti-6xHis primary mouse antibody at a 1:1,000 dilution and horseradish peroxidase (HRP)-conjugated goat anti-mouse IgG secondary antibody at a 1:5,000 dilution. The blots were developed using SuperSignal West Pico Chemiluminescent Substrate (Pierce), imaged and analyzed by the Bio-Rad Gel Imaging System.

Cell culture and protein treatment. Human erythroleukemia K562 cells and the basophilic leukemia KU812 cells, both of which were leukemia cells derived from the patients with CML at blast crisis, were obtained from the American Type Culture Collection (Manassas, VA) and cultured in RPMI1640 medium supplemented with $10 \%$ fetal calf serum, $2 \mathrm{mM}$ L-glutamine and antibiotics $(100 \mathrm{U} / \mathrm{ml}$ penicillin and $100 \mu \mathrm{g} /$ $\mathrm{ml}$ streptomycin) at $37^{\circ} \mathrm{C}$ in a humidified atmosphere of $5 \%$ $\mathrm{CO}_{2}$. Culture media changes were performed routinely, and the exponentially growing cells were used to conduct the following experiments. For the protein functional experiment, K562 cells or KU812 cells $\left(5 \times 10^{5}\right.$ cells $\left./ \mathrm{ml}\right)$ were treated with $\mathrm{scFv}$ or bovine serum albumin (BSA) (as a negative control) at $37^{\circ} \mathrm{C}$ for $6 \mathrm{~h}$ at various final concentrations ranging from 0 to $103 \mu \mathrm{g} / \mathrm{ml}$ in the complete medium.

Indirect enzyme-linked immunosorbent assay. The binding activity of the recombinant protein $\mathrm{ScFv}$ was determined by cell membrane-ELISA (CM-ELISA) using biological active membranes of tumor cells as described by Tur et al $(21,22)$. In brief, 96-well plates were coated with $100 \mu 1(\sim 0.9 \mathrm{mg}$ protein/ml) freshly prepared membrane fractions of the CML cell line $\mathrm{K} 562$ in $0.02 \mathrm{M}$ bicarbonate buffer ( $\mathrm{pH}$ 9.6) overnight at $4^{\circ} \mathrm{C}$. The plates were washed three times with PBS ( $\left.\mathrm{pH} 7.4\right)$ containing $0.2 \%(\mathrm{v} / \mathrm{v})$ Tween-20 (TPBS) and blocked with $200 \mu 110 \%$ fetal bovine serum in PBS. Then $0.01-103 \mu \mathrm{g} / \mathrm{ml}$ scFv or BSA diluted with $10 \%$ fetal bovine serum, and $0.05 \%$ Tween-20 (v/v) in PBS was added to the plate and incubated at $37^{\circ} \mathrm{C}$ for $1 \mathrm{~h}$. After washing with PBS containing $0.05 \%$ Tween-20, $100 \mu 1$ of anti-6xHis mouse monoclonal antibody

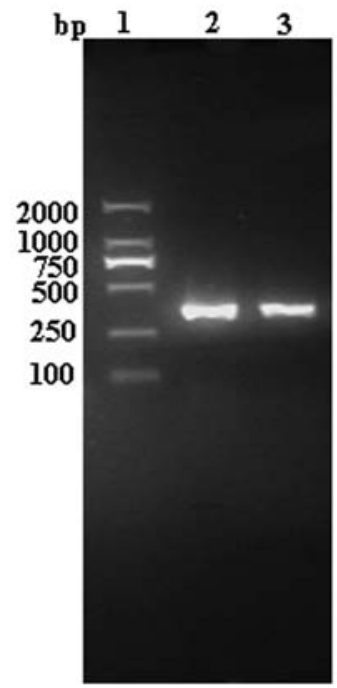

Figure 1. The amplification of VH and VL. Lane 1, DNA ladder (DL2000); lane 2, VH; lane 3, VL.

(ZhongShan GoldenBridge) in 1:1,000 was added to the plates and incubated for $1 \mathrm{~h}$ at $37^{\circ} \mathrm{C}$. After washing the plate three times, bound scFv protein was detected with HRP-conjugated goat anti-mouse IgG antibody. The assay was developed using an 3,3',5,5'-tetramethyl benzidine dihydrochloride (TMB) solution (KeHua Co., Shanghai, China) and the absorbance at $450 \mathrm{~nm}$ was measured by a microplate reader (Molecular Devices, Ismaning, Germany). The binding activity of $\mathrm{scFv}$ was determined by subtracting the absorbance of background binding from the value obtained with a scFv.

Flow cytometric analysis of scFv cancer-targeting ability in vitro. To identify the cancer-targeting ability of anti-CML cells scFv in vitro, flow cytometric analysis was performed on the CML cells (K562 and KU812 cells), along with the non-CML related cells (as a negative cell). All cells were respectively collected from culture flasks, washed and resuspended $\left(1 \times 10^{6}\right.$ cells $\left./ \mathrm{ml}\right)$ in PBS. After blocking, cells were incubated with anti-CML $\mathrm{scFv}(100 \mu \mathrm{g} / \mathrm{ml})$ or BSA $(10 \mu \mathrm{g} / \mathrm{ml})$ for $1 \mathrm{~h}$ at $37^{\circ} \mathrm{C}$. After three rounds of washing, anti-6xHis mouse monoclonal antibody was added for $1 \mathrm{~h}$ at $37^{\circ} \mathrm{C}$. After washing the plate, a FITCconjugated goat anti-mouse $\mathrm{IgG}$ antibody for $\mathrm{scFv}$ was added to each sample and incubated for $30 \mathrm{~min}$ at $37^{\circ} \mathrm{C}$. The cells were then washed with PBS and analyzed with FACScalibur flow cytometer (Becton-Dickinson, Cowley, UK).

\section{Results}

Cloning of pET32a-scFv. The VH and VL were amplified from cDNA (Fig. 1). By the comparison analysis of threedimensional conformation structure, the prepared humanized $\mathrm{scFv}$ fragment had a similar conformation with the known anti-hepatic cancer cell scFv fragment (GenBank accession no. AY686498), indicating that the humanized scFv fragment was constructed successfully (Fig. 2). Amplification products of approximately 732 bp were obtained using the specific primers for the $\mathrm{scFv}$, which were subsequently cloned into pET32a(+) expression vector. The prokaryotic expression vector pET32a-scFv was successfully constructed as proven 


\begin{tabular}{|c|c|c|c|c|}
\hline & TGGT & TGGGGC & GTGAAGAAGC & CTGGG \\
\hline GTGAAGGTC & TCCTGCAAGG & CTTCTGGCTA & CACGTTCACC & $\frac{\text { AGCTACTGGA }}{\text { VH-CDR1 }}$ \\
\hline TGCACTGGGT & GCGACAGGCC & CCTGGACAAG & GGCTTGAGTG & GATGGGATGG \\
\hline ATTGATCCTT & ACGATAGTGA & $\frac{\text { AACTAACTAT }}{\text { VH-CDR2 }}$ & GCACAGAAGT & ITCAGGGCAG \\
\hline GGTCACCATG & ACCAGGGACA & CGTCCATCAG & CACAGCCTAC & ATGGAGCTGA \\
\hline GCAGGCTGAG & ATCTGACGAC & ACGGCCGTGT & ATTACTGTGC & AAGATATGGT \\
\hline$\frac{\text { TACGACGGGA }}{\text { VH-CDR3 }}$ & $\underline{\text { CGGGGTTTGC }}$ & TTACTGGGGC & CAAGGGACCA & CGGTCACCGT \\
\hline СТССТCATCA & $\underline{\text { GGAGGAGGCG }}$ & GATCCGGAGG & CGGTGGATCT & $\underline{\text { GGAGGCGGTG }}$ \\
\hline GATCCO & & & $\begin{array}{l}\text { Linker } \\
\text { CCTCCTTGGC }\end{array}$ & \\
\hline GGACAGAGG & $\begin{array}{l}\text { TGTGCTGA } \\
\text { GCCACCATC }\end{array}$ & $\begin{array}{l}\text { CAGTCTCCAG } \\
\text { CCTGCAGAGC }\end{array}$ & $\begin{array}{l}\text { CCTCCTTGGC } \\
\text { CAGTAAAAGT }\end{array}$ & $\begin{array}{l}\text { CGTGT } \\
\text { GTCAC }\end{array}$ \\
\hline & GCCACCATC & CCTGCAGAGC & & L-CDR1 \\
\hline CTGGCTATAG & ITATATTCAC & TGGTATCAGC & AGAAACCAGG & ACAACCTCCTA \\
\hline AACTCCTGAT & TTACCTTGTA & $\frac{\text { ICCAATAAAG }}{\text { VL-CDR2 }}$ & $\underline{\mathrm{ACACTGGGGT}}$ & CCCAGCCAGG \\
\hline TTCA & GTGGC & GACCGATTTC & ACCCTCACAA & TTAATCCTGT \\
\hline GGAAGCTAAT & GATACTGCAA & ATTATTACTG & TCAGCACATT & AGGGAGCI \\
\hline & & & & CDKs \\
\hline ACGTTC & & . & & \\
\hline
\end{tabular}

Figure 2. Nucleotide sequences of the humanized scFv.
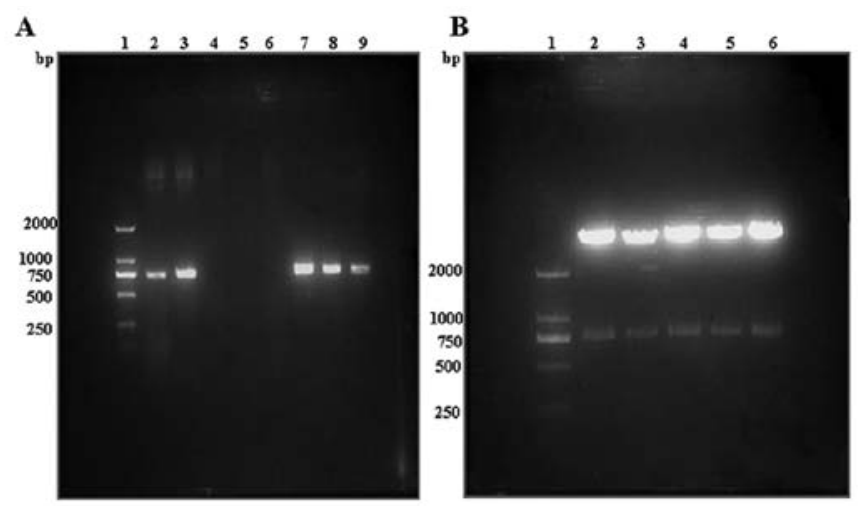

Figure 3. Cloning of the target pET32a-scFv. (A) Bacterial colony PCR for the detection of the DH5 $\alpha$ clones. Lane 1, DNA ladder (DL2000); lanes 2-3, and 7-9, positive bacterial colonies for pET32a-scFv; lanes 4-6, the negative bacterial colony pET32a-scFv. (B) Double endonuclease digestion of the prokaryotic expression vector pET32a-scFv. Lane 1, DNA ladder (DL2000); lanes 2-6, double digestion with EcoRI/HindIII.

by bacterial colony PCR (Fig. 3A), restriction enzyme digestions (Fig. 3B), and complete sequencing (Fig. 2).

Expression and purification of the $s c F v$ recombinant protein. The prokaryotic expression vector pET32a-scFv was transformed into the $E$. coli BL21 (DE3) expression host strain for protein overexpression. A small-scale time course experiment was performed to determine the kinetics of protein expression in the bacterial culture. It was determined that the cells should be harvested at $4 \mathrm{~h}$ after IPTG induction, as the maximum amount of the correct $46 \mathrm{kDa}$ size soluble scFv protein which contained the His-tag protein was produced at this time point (Fig. 4A). The solubility of the expressed protein at $4 \mathrm{~h}$ was further investigated in detail. Cell pellets were abruptly frozen on dry ice and underwent a freeze thaw cycle. The cells were then sonicated (Branson Sonifier 250, Branson, Danbury, CT, USA) and the sample was clarified by centrifugation to separate the clear lysate containing the soluble protein from the cell debris pellet. Most of the target protein was detected in the

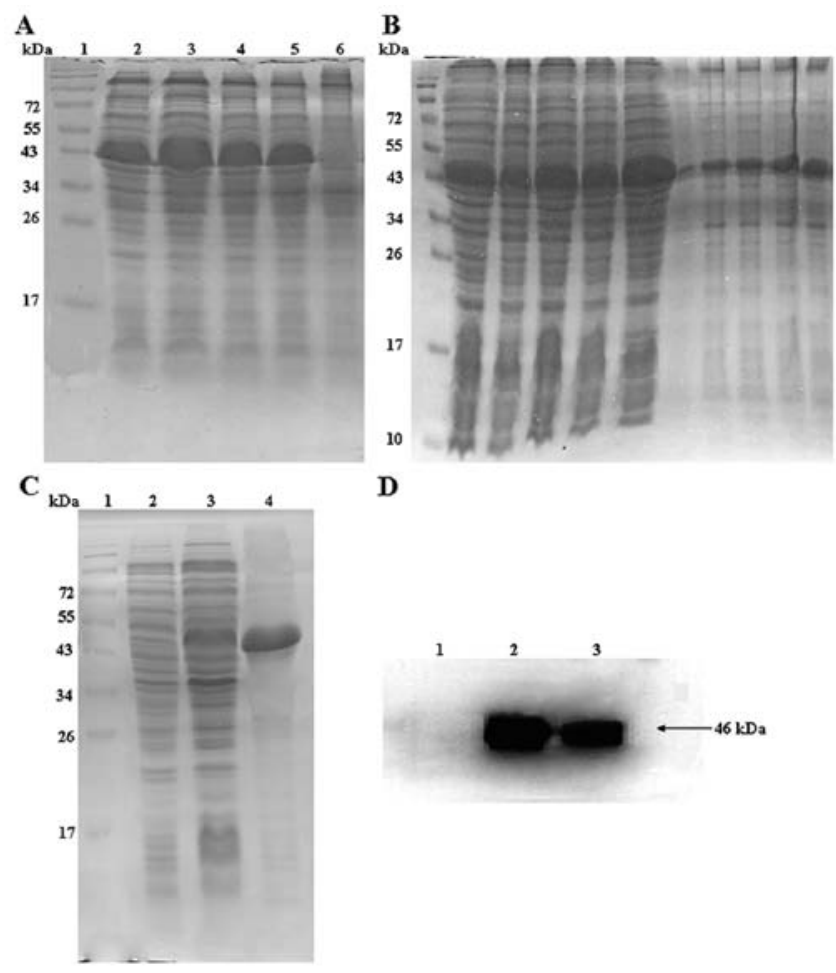

Figure 4. Expression and purification of the scFv protein in E. coli containing pET32a-scFv. (A) Time course analysis of scFv protein expression 3-6 h after IPTG induction by SDS-PAGE. Samples of bacterial culture were taken every hour starting at $3 \mathrm{~h}$ and up to $6 \mathrm{~h}$ after IPTG induction. The cell pellets from each time point were suspended in 1 X SDS protein loading buffer, boiled for $5 \mathrm{~min}$ at $100^{\circ} \mathrm{C}$, centrifuged at $10,000 \mathrm{x}$ g for $10 \mathrm{~min}$ and the supernatant was collected for $10 \%$ SDS-PAGE analysis. Lane 1, molecular weight standards; lanes 2-5, hourly induction samples (3-6 h); lane 6, uninduced culture. (B) Solubility analysis of the $\mathrm{scFv}$ protein by $10 \%$ SDS-PAGE. The cell pellets collected from the protein expression cultures induced for $4 \mathrm{~h}$ were lysed, sonicated and centrifuged. The clear lysate was analyzed by SDS-PAGE as the soluble fraction and the remaining cell pellet as the insoluble fraction. Lane 1, molecular weight standard; lanes 2-6, soluble fraction; lanes 7-11, cell pellet. (C) Purification of the his-tagged $\mathrm{scFv}$ recombinant protein by $\mathrm{Ni}^{2+}$-NTA metal affinity chromatography. Lane 1 , molecular weight standard; lane 2, uninduced bacterial lysate; lane 3, IPTG induced culture; lane 4, purified protein. (D) Detection of scFv by western blotting using anti-6xHis antibody. Lane 1, uninduced bacterial lysate; lane 2, IPTG induced culture; lane 3 , purified protein.

clear lysate (Fig. 4B). Therefore, the recombinant 6xHis-scFv protein was expressed in a soluble form in the bacterial cells. The $\mathrm{scFv}$ protein was expressed as a recombinant fusion protein with His-tag, consisting of $\mathrm{scFv}$ and other for His-tag and its upstream sequence, which was consistent with the theoretically predicted value $(46 \mathrm{kDa})$. The expression and purification was identified by $10 \%$ SDS-PAGE gel and Coomassie brilliant blue staining (Fig. 4C). Sodium dodecyl sulfate polyacrylamide gel electrophoresis (SDS-PAGE) analysis showed that the purity of the prepared $\mathrm{scFv}$ was $>90 \%$ and the concentration was $7.8 \mathrm{mg} / \mathrm{ml}$, which demonstrated its potential usefulness in clinical application. Moreover, the expression and purification of the recombinant protein was validated by immunoblotting (Fig. 4D) using anti-6xHis antibody.

Cell membrane binding activity of the recombinant $s c F v$ antibodies. The anti-CML cells scFv, prepared by immunizing BALB/c mice with CML patient cells, can be used for 


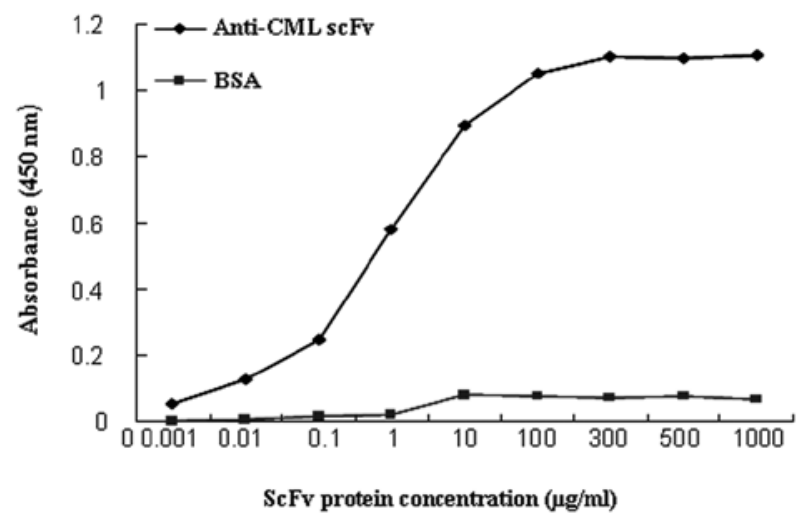

Figure 5. Analysis of the cell membrane binding activity of purified antiCML cells scFv by CM-ELISA. A 96-well microtiter plate was coated with the freshly extracted cell membrane fractions and probed with various concentrations of anti-CML cells scFv. Anti-CML cells scFv was purified from E. coli cultures and its binding activity to antigen (CML cell surface antigen) was analyzed by ELISA. BSA was used as a negative control.
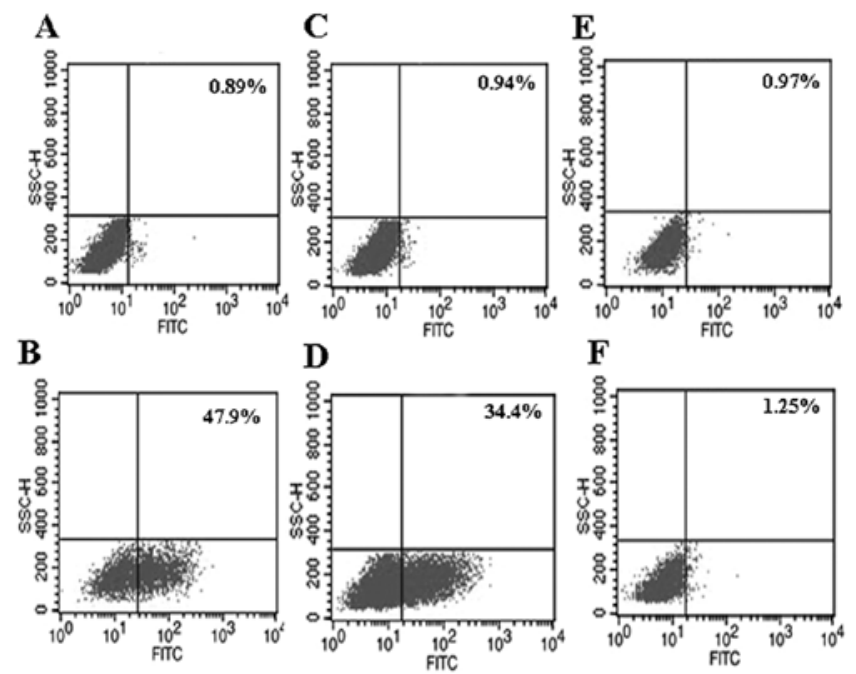

Figure 6. Flow cytometric analysis for cancer-targeting activity of anti-CML cells scFv in vitro. K562, KU812 were incubated with anti-CML cells scFv or BSA and then incubated with mouse anti-6xHis monoclonal antibody, and accordingly stained with FITC-conjugated anti-mouse $\mathrm{IgG}$ for $\mathrm{scFv}$ and analyzed. HEK 293 cells as a negative control. The fluorescence on cells stained with anti-CML cells scFv or BSA was shown. The binding rates of K562 and KU812 cells with scFv were (A and B) $47.9 \%$, (C and D) $34.4 \%$, respectively, while that of HEK293 cell was (E and F) only 1.25\%. (A, C and E) The cells were treated with BSA and (B, D and F) were treated with anti-CML cells scFv.

membrane targeting of fusion proteins. To identify whether the $\mathrm{scFv}$ recognizes and has high binding activity to the CML cell membrane components, CM-ELISA was performed. The ELISA plate was coated with freshly prepared membrane fractions of the CML cell line K562 and detected by incubation with anti-6xHis mouse monoclonal antibody and HRP-conjugated goat anti-mouse IgG antibody. The results of CM-ELISA, revealed that the anti-CML cells ScFv showed high binding activity to the cell membrane of K562 compared with the control (Fig. 5).

Cancer-targeting ability of anti-CML scFv in vitro. To identify the different expression rate of the targeting antigen on K562, KU812 and the non-CML related cells, flow cytometric analysis was conducted. Anti-CML cells $\mathrm{scFv}$ interacted with $47.9 \%$ of K562 cells (Fig. 6A and B) and 34.4\% of KU812 cells (Fig. 6C and D) versus $1.25 \%$ of the non-CML related cells (Fig. 6E and F), which demonstrated that the targeting antigen was highly expressed on CML cells (K562 and KU812 cells) and there was hardly any expression on the non-CML related cells.

\section{Discussion}

In the recent years, recombinant antibody fragments against tumor cell surface antigens have been produced successfully for tumor diagnostic and therapeutic applications (23). With the advances of gene recombinant technology and other biotechniques, antibody preparing, screening and the costeffectiveness of large-scale antibody production have acquired great progress in this field. The products originated from scFvs could allow us to avoid the major limitations previously observed when administering murine intact mAbs to cancer patients. A number of scFv-based biological products are continuously entering clinical trials but many aspects remain to be elucidated and procedure improvements are needed before the scFvs could be routinely used for diagnostic and therapeutic applications. Among the most critical issues, careful monitoring of toxicity, improvement of the $\mathrm{scFv}$ capacity of penetrating tumors and deeper characterization of immunoregulatory pathways and molecular mechanisms of growth regulation are also needed for further study. Also, the potential of scFvs as diagnostic reagents has not been fully explored.

Likewise, the use of mAbs has greatly improved the treatment of patients with lymphoma and leukemia. Rituximab (anti-CD20) was the first mAb developed for the treatment of B-cell lymphomas and has significant activity in chronic lymphocytic leukemia (CLL) (24). In recent years, many antibodies are developed for hematologic tumors, for example alemtuzumab (anti-CD52) for untreated or refractory CLL patients (25); gemtuzumab ozogamicin (GO, anti-CD33) for acute myeloid leukemia and myelodysplastic syndromes (26); and ofatumumab (Hu-Max-CD20) (27). Many mAbs developed against all these antigens have been further developed in the $\mathrm{scFv}$ format to improve therapeutic performance in patients $(28,29)$.

There is a high incidence of CML. The most effective treatment for CML is allogeneic hematopoietic stem cell transplantation, but age, physical condition and other factors limit the application of this method, and graft-versus-host disease, the incidence of opportunistic infections and other complications may lead to death. Although BCR/ABL tyrosine kinase inhibitors can specifically inhibit BCR/ABL protein-positive leukemia cell proliferation and induce apoptosis, patients still may have the possibility of relapse or resistance, leading to irreversible malignant progression. Therefore, exploring other more effective treatments is urgently needed for the treatment of CML. In a previous study, we immunized BALB/c mice with CML patient cells to prepare a monoclonal antibodies library against CML cell surface antigens (unpublished data). From these prepared monoclonal antibodies, we screened one of them specifically against CML patient cells to prepare our anti-CML cells scFv. In this study, we have cloned, 
overexpressed, purified, retrieved, and identified the prepared humanized anti-CML cells scFv in E. coli.

However, expression of foreign proteins at high levels in $E$. coli often results in the formation of inclusion bodies (30), which are composed of insoluble aggregates of the expressed protein. Generally, procedures such as washing, denaturation, purification, refolding and concentration are needed in order to obtain an effective target recombinant protein (31). The prepared $\mathrm{scFv}$ protein expressed mostly in the soluble form which suggested that the $E$. coli protein expression system can effectively be used for producing humanized scFv. Besides, the T7 promoter system of pET32a(+) has the advantage of highlevel expression, which was an important factor to have $\mathrm{scFv}$ expression at high levels. Here, we have selected an anti-CML cell $\mathrm{scFv}$ based on its ability binding to the CML cells in vitro. After sequencing, it was demonstrated that it is composed of the CDRs of the mouse antibody and the FRs of the human antibody with the highest homology. Although CDR grafting could make antibodies less immunogenic and could reduce affinity compared to the parent murine antibody (32), we have found that the selected ScFv has high specificity and affinity to CML cells in this study. This scFv maintains its antigen-binding activity as shown in flow cytometric and ELISA analyses. Moreover, anti-CML cells ScFv has cancer-targeting activity to CML cells in vitro, as it can specifically bind to human erythroleukemia K562 cells and the basophilic leukemia KU812 cells but not to non-CML related cell line. In our further studies, some other remodeling methods of antibodies, such as resurfacing, could be considered to increase the affinity of scFv.

Furthermore, as shown in flow cytometric analyses, antiCML cell $\mathrm{scFv}$ is capable of targeting CML cells, while there is no binding to non-CML tumor cells. The in vitro binding of anti-CML cell scFv to CML cell lines shows promise for targeting CML cells in vivo. Further studies are underway to test the cancer-targeting potentials of anti-CML cells $\mathrm{scFv}$ in vivo. Moreover, they can be used to develop therapies based on targeting delivery strategies. For example, the scFv can be fused with drugs or drug-loaded nanoparticles, engineered toxin molecules, or appropriate radionuclides to obtain a targeted cell killing function $(33,34)$. These targeted agents could offer an opportunity to determine if in vivo eliminating of tumor-initiating cells results in improved therapeutic effects such as suppression of recurrence in theory.

In conclusion, we have characterized a highly efficient model for the generation of humanized $\mathrm{scFv}$ with potential clinical diagnostic and therapeutic applications. We constructed a humanized scFv from a selected anti-CML patient cells monoclonal antibody library. Our results suggest that this constructed $\mathrm{scFv}$ has high specificity and affinity to CML cells and can specifically bind to CML cells. In future, anti-CML $\mathrm{scF}$ can be conjugated with drugs or drug-loaded nanoparticles, engineered toxin molecules, or appropriate radionuclides to impart a targeted cell killing function for CML diagnosis and therapeutics.

\section{Acknowledgements}

This study was supported by the National Science Foundation of China Grant no. 30871102 to W.L.F. and the Doctor Foundation of Chongqing Medical University 2008 to D.W.

\section{References}

1. Köhler G and Milstein C: Continuous cultures of fused cells secreting antibody of predefined specificity. Nature 256: 495-497, 1975.

2. Liu XY, Pop LM, Tsai L, Pop IV and Vitetta ES: Chimeric divalent and tetravalent anti-CD19 monoclonal antibodies with potent in vitro and in vivo antitumor activity against human B-cell lymphoma and pre-B acute lymphoblastic leukemia cell lines. Int J Cancer 129: 497-506, 2011.

3. Martin SJ and Duvic M: Treatment of cutaneous lymphoid hyperplasia with the monoclonal anti-CD20 antibody rituximab. Clin Lymphoma Myeloma Leuk 11: 286-288, 2011.

4. Mirick GR, Bradt BM, Denardo SJ and Denardo GL: A review of human anti-globulin antibody (HAGA, HAMA, HACA, HAHA) responses to monoclonal antibodies. Not four letter words. Q J Nucl Med Mol Imaging 48: 251-257, 2004.

5. Borsi L, Balza E, Bestagno M, et al: Selective targeting of tumoral vasculature: comparison of different formats of an antibody (L19) to the ED-B domain of fibronectin. Int J Cancer 102: 75-85, 2002.

6. Goel A, Beresford GW, Colcher D, Pavlinkova G, Booth BJ, Kortylewicz JB and Batra SK: Divalent forms of CC49 singlechain antibody constructs in Pichia pastoris: expression, purification, and characterization. J Biochem 127: 829-836, 2000.

7. Arakawa F, Yamamoto T, Kanda H, Watanabe T and Kuroki M: cDNA sequence analysis of monoclonal antibody FU-MK-1 specific for a transmembrane carcinoma-associated antigen, and construction of a mouse/human chimeric antibody. Hybridoma 18: 131-138, 1999.

8. Allison DE, Gourlay SG, Koren E, Miller RM and Fox JA: Pharmacokinetics of rhuMAb CD18, a recombinant humanised monoclonal antibody fragment to CD18, in normal healthy human volunteers. BioDrugs 16: 63-70, 2002.

9. Kim DJ, Chung JH, Ryu YS, Rhim JH, Kim CW, Suh Y and Chung HK: Production and characterisation of a recombinant $\mathrm{scFv}$ reactive with human gastrointestinal carcinomas. Br J Cancer 87: 405-413, 2002.

10. Al-Yasi AR, Carroll MJ, Ellison D, et al: Axillary node status in breast cancer patients prior to surgery by imaging with Tc-99m humanized anti-PEM monoclonal antibody, hHMFG1. Br J Cancer 86: 870-878, 2002.

11. Bird RE, Hardman KD, Jacobson JW, et al: Single-chain antigenbinding proteins. Science 242: 423-426, 1988.

12. Lu RM, Chang YL, Chen MS and Wu HC: Single chain anti-cMet antibody conjugated nanoparticles for in vivo tumor-targeted imaging and drug delivery. Biomaterials 32: 3265-3274, 2011

13. Wang H, Liu X, He Y, et al: Expression and purification of an anti-clenbuterol single chain Fv antibody in Escherichia coli. Protein Expr Purif 72: 26-31, 2010.

14. Naumann JM, Küttner G and Bureik M: Expression and secretion of a CB4-1 scFv-GFP fusion protein by fission yeast. Appl Biochem Biotech 163: 80-89, 2011 .

15. Ohshima $M$, Inoue $K$, Hayashi $H$, Tsuji D, Mizugaki $M$ and Itoh K: Generation of AcGFP fusion with single-chain Fv selected from a phage display library constructed from mice hyperimmunized against 5-methyl 2'-deoxycytidine. Protein Eng Des Sel 23: 881-888, 2010.

16. Vielemeyer O, Nizak C, Jimenez AJ, et al: Characterization of single chain antibody targets through yeast two hybrid. BMC Biotechnol 10: 59, 2010.

17. Chen Y, Huang K, Li X, Li X, Zhu Z and Wu Y: Generation of a stable anti-human CD44v6 scFv and analysis of its cancertargeting ability in vitro. Cancer Immunol Immunother 59: 933-942, 2010.

18. Wiiger MT, Gehrken HB, Fodstad $\varnothing$, Mælandsmo GM and Andersson Y: A novel human recombinant single-chain antibody targeting CD166/ALCAM inhibits cancer cell invasion in vitro and in vivo tumour growth. Cancer Immunol Immunother 59: 1665-1674, 2010.

19. Crépin R, Goenaga AL, Jullienne B, et al: Development of human single-chain antibodies to the transferrin receptor that effectively antagonize the growth of leukemias and lymphomas. Cancer Res 70: 5497-5506, 2010.

20. Accardi L and Di Bonito P: Antibodies in single-chain format against tumour-associated antigens: present and future applications. Curr Med Chem 17: 1730-1755, 2010.

21. Tur MK, Huhn M, Sasse S, Engert A and Barth S: Selection of scFv phages on intact cells under low $\mathrm{pH}$ conditions leads to a significant loss of insert-free phages. Biotechniques 30: 404-413, 2001. 
22. Tur MK, Rothe A, Huhn M, et al: A novel approach for immunization, screening and characterization of selected scFv libraries using membrane fractions of tumor cells. Int J Mol Med 11: 523-527, 2003

23. Qiu JK, Jung ST, Georgiou G and Hang HY: Enrichment of Escherichia coli spheroplasts displaying $\mathrm{scFv}$ antibodies specific for antigens expressed on the human cell surface. Appl Microbiol Biot 88: 1385-1391, 2010.

24. White CA, Larocca A and Grillo-López AJ: Anti-CD20 monoclonal antibodies as novel treatments for non-Hodgkin's lymphoma. Pharm Sci Technol Today 2: 95-101, 1999.

25. Rodon P, Breton P and Courouble G: Treatment of pure red cell aplasia and autoimmune haemolytic anaemia in chronic lymphocytic leukaemia with Campath-1H. Eur J Haematol 70: 319-321, 2003.

26. Yamaguchi Y, Usui N, Dobashi N, et al: Gemtuzumab ozogamicin (GO) in relapsed/refractory patients with acute myeloid leukemia. Gan To Kaqaku Ryoho 36: 1105-1109, 2009.

27. Robak T: Ofatumumab, a human monoclonal antibody for lymphoid malignancies and autoimmune disorders. Curr Opin Mol Ther 10: 294-309, 2008.

28. Krauss J, Arndt MA, Vu BK, Newton DL, Seeber S and Rybak SM: Efficient killing of CD22 ${ }^{+}$tumor cells by a humanized diabody-RNase fusion protein. Biochem Biophys Res Commun 331: 595-602, 2005
29. Braschoss S, Hirsch B, Dübel S, Stein H and Dürkop H: New anti-CD30 human pancreatic ribonuclease-based immunotoxin reveals strong and specific cytotoxicity in vivo. Leuk Lymphoma 48: 1179-1186, 2007.

30. Moore JT, Uppal A, Maley F and Maley GF: Overcoming inclusion body formation in a high-level expression system. Protein Expr Purif 4: 160-163, 1993.

31. Su L, Chen SS, Yang KG, Liu CZ, Zhang YL and Liang ZQ: High-level expression of human stem cell factor fused with erythropoietin mimetic peptide in Escherichia coli. Protein Expr Purif 47: 477-482, 2006.

32. Jones PT, Dear PH, Foote J, Neuberger MS and Winter G: Replacing the complementarity-determining regions in a human antibody with those from a mouse. Nature 321: 522-525, 1986.

33. Weiner LM, Dhodapkar MV and Ferrone S: Monoclonal antibodies for cancer immunotherapy. Lancet 373: 1033-1040, 2009.

34. Adams GP, Tai MS, McCartney JE, et al: Avidity-mediated enhancement of in vivo tumor targeting by single-chain Fv dimers. Clin Cancer Res 12: 1599-1605, 2006. 